Session 3530

\title{
Using Portfolios for Exit Assessment in Engineering Programs
}

\author{
Doris R. Brodeur \\ Massachusetts Institute of Technology
}

\begin{abstract}
The Department of Aeronautics and Astronautics at the Massachusetts Institute of Technology is designing a portfolio assessment system to assess students' achievement of program outcomes. In the past three years, the undergraduate aerospace engineering program has embarked upon major curriculum reform initiatives centered on 16 program outcomes detailed in its CDIO Syllabus. Portfolios will be organized into categories reflecting these outcomes. (The $16 \mathrm{CDIO}$ skills, or program outcomes, are also the cornerstone of the program's self-study report for ABET accreditation.) This paper addresses the planning and development of portfolios for assessing students' achievement at the end of their programs in aerospace engineering at MIT.
\end{abstract}

\section{Background}

In its strategic plan of 1998, the Department of Aeronautics and Astronautics at the Massachusetts Institute of Technology (MIT) committed to major reform of its curriculum, teaching and learning methods, and laboratory environments. To achieve its goals, the department framed its curriculum to model a product system life cycle. The four phases in the curriculum are referred to as Conceive-Design-Implement-Operate $(C D I O)$. The Conceive stage includes defining the need and technology, considering the enterprise strategy and regulations, developing the concept, architecture, and business case. The second stage, Design, focuses on creating the design, i.e., the plans, drawings, and algorithms that describe what will be implemented. Implement refers to the transformation of the design into the product, including manufacturing, coding, test and validation. The final stage, Operate, uses the implemented product to deliver the intended value, including maintaining, evolving and retiring the system.

Curriculum reform efforts centered on a set of 16 key learning outcomes deemed essential for new engineers. (See Table 1) These outcomes, categorized as technical, personal, interpersonal, and CDIO system skills, were validated in surveys of faculty, students, alumni, and industrial representatives, both in the United States and in Sweden. They serve as the program outcomes of MIT's two aerospace education programs accredited by ABET under its new evaluation criteria and policies. ${ }^{1}$ The more detailed list of outcomes, called the CDIO Syllabus, is available at the CDIO Web-site. ${ }^{2}$ Here, the 16 program outcomes are outlined in two additional levels of detail. 
Table 1. Program Outcomes for Aeronautics and Astronautics at MIT

\begin{tabular}{|c|c|c|}
\hline $\begin{array}{l}1.0 \\
\text { Technical Skills }\end{array}$ & $\begin{array}{l}4.1 \\
4.2 \\
4.3\end{array}$ & $\begin{array}{l}\text { Demonstrate a capacity to use the principles of the } \\
\text { underlying sciences of mathematics, physics, } \\
\text { chemistry, and biology. } \\
\text { Apply the principles of core engineering } \\
\text { fundamentals. } \\
\text { Demonstrate deep working knowledge of } \\
\text { professional engineering. }\end{array}$ \\
\hline $\begin{array}{l}2.0 \\
\text { Personal and } \\
\text { Professional } \\
\text { Skills }\end{array}$ & $\begin{array}{l}4.4 \\
4.5 \\
4.6 \\
4.7 \\
4.8\end{array}$ & $\begin{array}{l}\text { Analyze and solve engineering problems. } \\
\text { Conduct inquiry and experimentation in engineering } \\
\text { problems. } \\
\text { Think holistically and systemically. } \\
\text { Master personal skills that contribute to successful } \\
\text { engineering practice: initiative, flexibility, creativity, } \\
\text { curiosity, and time management. } \\
\text { Master professional skills that contribute to } \\
\text { successful engineering practice: professional ethics, } \\
\text { integrity, currency in the field, career planning. }\end{array}$ \\
\hline $\begin{array}{l}.0 \\
\text { Interpersonal } \\
\text { Skills }\end{array}$ & $\begin{array}{l}4.9 \\
4.10\end{array}$ & $\begin{array}{l}\text { Lead and work in teams. } \\
\text { Communicate effectively in writing, in electronic } \\
\text { form, in graphic media, and in oral presentations. }\end{array}$ \\
\hline $\begin{array}{l}4.0 \\
\text { CDIO System } \\
\text { Skills }\end{array}$ & $\begin{array}{l}4.11 \\
4.12 \\
4.13\end{array}$ & $\begin{array}{l}\text { Recognize the importance of the societal context in } \\
\text { engineering practice. } \\
\text { Appreciate different enterprise cultures and work } \\
\text { successfully in organizations. } \\
\text { Conceive engineering systems including setting } \\
\text { requirements, defining functions, modeling, and } \\
\text { managing projects. } \\
\text { Design complex systems. } \\
\text { Implement hardware and software processes and } \\
\text { manage implementation procedures. } \\
\text { Operate complex systems and processes and manage } \\
\text { operations. }\end{array}$ \\
\hline
\end{tabular}

Concurrent with its curriculum reform, the department has embarked upon several initiatives to improve teaching, learning, and assessment practices. Within courses, faculty are using traditional and newly designed tools to assess student achievement of course learning objectives. Beginning in Fall 2002, a portfolio assessment system will be used to get a more complete measure of overall student achievement of the 16 program objectives and to evaluate the effectiveness of the department's educational reforms. 


\section{Portfolio Assessment in Engineering}

The use of portfolios to assess student achievement has a long history in disciplines such as art and architecture. In the past ten years, professional programs, such as teacher education, have required portfolios of candidates seeking certification or licensure. Portfolio use is growing in all disciplines in higher education, including engineering. Much of the interest in portfolio systems in the next few years will be in electronic formats, either Web-based or CD-ROM, or both. At present, the term 'portfolio' is used to describe files with very different purposes, from institutional promotional materials to personal Web pages to faculty tenure review dossiers to career planning documents. The American Association of Higher Education (AAHE) maintains a database, called The Portfolio Clearinghouse, which describes portfolio use at more than 50 colleges and universities. ${ }^{3}$ In the database, portfolios are classified by target population or level, content, purpose, and medium or format.

Portfolios serve many diverse purposes and levels in engineering programs, as well. They can be used to assess specific learning experiences within a course or program, the entire set of learning objectives of a single course, entire programs, or combinations of these. The following examples, while not exhaustive, illustrate the variety of portfolio use in engineering. The mechanical engineering major at the U. S. Coast Guard Academy uses an institutional design portfolio to evaluate the design experiences in its curriculum. ${ }^{4}$ The portfolio states the department's philosophy of design education as a developmental process, and documents, using selected design experiences, how that philosophy is put into practice. This portfolio differs from others in that instructors, not students, compile it. It is similar to what we at MIT call reflective memos, i.e., opportunities for instructors to reflect on course learning objectives and how students have met them. Another example of portfolio use for specific learning experiences is found in Introduction to Aerospace Engineering at MIT, where each student creates a design portfolio to document progress and achievement as a part of a group that designs, builds, flies, and races a lighter-than-air vehicle. ${ }^{5}$

Individual instructors often use student portfolios to assess the learning outcomes for their courses. At Ohio State University and Louisiana State University, portfolios were the primary instrument for evaluating learning and were used to demonstrate mastery of core competencies in two courses in biological engineering. ${ }^{6}$ At James Madison University, Handley uses portfolios in chemistry courses in an engineering technology program to help students see connections between chemistry principles and their laboratory applications. ${ }^{7}$ In an aerodynamics course at San Jose State University, Mourtos gives students options in learning activities and assignments that will demonstrate their achievement of course learning objectives. Students collect their work into portfolios with their reflections on the meaning and value of their learning experiences. ${ }^{8}$

The Colorado School of Mines uses portfolios to assess engineering programs. ${ }^{9}$ As part of a continuous improvement process, a statistical sample of students is drawn from each entering class. Portfolios are developed for each student in the sample to track entering 
capabilities and achievement at the end of the program. Portfolio entries are determined by the program and collected from student records, and or, course instructors. The assessment portfolio for aerospace engineering at MIT will ultimately be used to evaluate program outcomes and the revised curriculum. However, the portfolio' s key purpose will be to evaluate each student's achievement of the 16 technical, personal, interpersonal, and CDIO system skills.

The purpose of our portfolio assessment system is a combination of those found in the examples. It is similar to the system used in the environmental engineering program at Wentworth Institute of Technology, in which students are asked to demonstrate their achievement of twelve general institute objectives and nine specific program objectives. ${ }^{10}$ The implementation and assessment differ from ours, but the overall purpose is similar.

In Aero/Astro at MIT, we define portfolios as purposeful collections of student work used to demonstrate mastery of specified learning outcomes, and as personal reflective tools for self-assessment. Drawings, designs, projects, video or audio presentations, and written material are combined to create a robust picture of a student. In addition to providing students with opportunities to demonstrate their skills, portfolios:

- document the progress of their educational experiences

- illustrate the processes of integration that have occurred during the learning process

- assess experiential learning and performance beyond factual knowledge

- provide students with opportunities for reflection and self-assessment

- determine how students' personal expectations have been met. ${ }^{11-12}$

Portfolios transfer much of the responsibility of demonstrating achievement of learning outcomes from the instructor to the student. Students are required to organize, synthesize, and clearly describe their achievements, and effectively communicate what they have learned. Creation of the portfolio, itself, can demonstrate achievement of several CDIO skills. (See Table 1) Portfolios encourage student creativity and allow students to emphasize educational experiences that are most relevant to them in more meaningful ways.

\section{Portfolio Components}

The components of a portfolio depend on its intended use. For example, does the department or the student or both retain the portfolio? Who selects the entries -- the student alone, instructor alone, department, or a combination of these? Will the portfolio include only the best results or track development over time? Will entries include written instructor comments or final editions without comments? Will the portfolio itself be assessed, i.e., will students receive a grade and/or credit for completing it? At MIT, we have not completed our discussions of these issues. For now, we propose portfolios consisting of these components. 
- Clear program outcomes: Program outcomes are already established and adopted. The portfolio will be structured around the 16 program outcomes found in the CDIO Syllabus and our ABET Self-Study Report.

- Indication of the relative importance of these outcomes: A survey of program constituents has established a rating from 1 (is aware of) to 5 (can lead in) for each of the program outcomes. These are indicated in the CDIO Syllabus.

- Personal expectations of the program: Students will be asked to list key expectations they have of the aeronautics and astronautics program as they begin the major in the second year. These will be reviewed, and revised if necessary, at the end of each academic year. At the end of the program, students will reflect on whether or not they were able to realize their own expectations, in addition to those specified by the program.

- Examples of evidence that demonstrate achievement of the intended outcomes: Possible artifacts include journals, writing samples, quizzes and exams, problem sets, reports, videotapes, CD's, designs, photographs, research projects, internships, selfassessment. The entries are produced in courses, internships, independent research, and extra-curricular projects throughout the students' time in the program. Coursework will have been previously graded, and students are encouraged to submit instructor and colleague comments with the work.

- Reflective statements accompanying each item: These statements are key to the portfolio assessment. They describe how the student went about mastering the materials and why the presented piece of evidence demonstrates mastery. These written commentaries portray how well students have grasped the concepts and content of various learning activities. They also help students reflect upon the personal impact and significance of their experiences ${ }^{13}$ The reflective statements include: 1) a description of the artifact or experience, 2) an explanation of the personal significance and impact of the artifact or experience, and 3) a discussion of the implications of that artifact or experience for the future

- Reflective statements introducing each section. The portfolio will be organized into four sections: technical expertise, personal skills, interpersonal skills, and CDIO system skills. Students will provide an introduction to the entries in each section, and a brief assessment of the level of competence achieved.

- Overall summary reflection: This commentary provides an overall self-assessment of the student with respect to the major program expectations and outcomes. In this section, the student also includes any personal expectations not already included. These written narratives give students opportunities to make connections among their experiences and recognize the overall context of their accomplishments.

Proceedings of the 2002 American Society for Engineering Education Annual Conference \& Exposition Copyright $\left({ }^{\circ}\right.$ 2002, American Society for Engineering Education 
- Description of future goals: This reflection is a brief statement of the student's intended direction, as well as an assessment of how well the program has prepared him/her to meet future challenges. This section can serve as an effective transition from the use of the portfolio for assessment purposes to its use as a personal career planning document.

\section{Portfolio Format}

The physical format of the portfolio can be paper-based, i.e., entries in folders or binders, multimedia with entries in boxes or cases, or electronic, i.e., $\mathrm{CD}$ or Web. Interest in electronic formats, or e-portfolios, is growing at many colleges and universities. Some are forming partnerships and coalitions to investigate systems that can be shared across institutions. The Urban Universities Portfolio Project is a collaboration of six urban public universities formed to develop prototype electronic institutional portfolios. The project is funded by the Pew Charitable Trusts and sponsored by AAHE. MIT is currently collaborating with several universities in identifying requirements for an electronic portfolio system. ${ }^{15}$ The goal of this group is to build a system that can be used for multiple types of portfolios and accommodate a number of computer systems. Consortium members will have full access to the software and its source code. ${ }^{16-17}$

One alternative to individual student portfolios is a database system that collects and organizes student entries across multiple programs. At Rose-Hulman Institute of Technology, an institute-wide committee designed and piloted a Web-based electronic portfolio system based on Oracle database software. ${ }^{18}$ The system is comprised of three components (input, output, and process) that include materials submission, modification of existing information, online rating and feedback, search capabilities, report generation, and security handling. The Institute is currently considering providing students with their individual electronic portfolios or CD-ROMS when they graduate.

In all formats, the student portfolio should be a creative personalized package, clearly organized with tables of contents, menus, and links (where appropriate). As we investigate electronic systems at MIT, the Aeronautics and Astronautics Department will implement a hybrid paper-based and personal Web-page format for portfolio assessment, giving students options for formatting. Eventually, we will migrate to an electronic environment.

\section{Procedures for Coaching and Advising Students}

At MIT, students declare a major and begin in our aerospace programs in the sophomore year. In an orientation seminar for new students, they are introduced to the department's CDIO Syllabus and recent initiatives in teaching, learning, and assessment. Beginning in Fall 2002, the orientation will also include an introduction to portfolios. Discussions with students will focus on benefits to them of creating personal portfolios and starting early. Students will be encouraged to begin their portfolios in their first semester, and continue

Proceedings of the 2002 American Society for Engineering Education Annual Conference \& Exposition Copyright (C) 2002, American Society for Engineering Education 
each semester until the end of their undergraduate program. Portfolios will be required for the class graduating in 2005, and offered as an option for students graduating earlier.

Program academic advisors, who currently assist students with course selection, academic support, and career direction, will serve as coaches for portfolio development. In orientation sessions, they will discuss guidelines and suggestions for helping students decide what to put in their portfolios and for guiding students to see meaning and connections among their experiences. Advisory checks are planned minimally for the end of the second and third years, but encouraged more often. Advisors will have a list of sample questions to help students in their portfolio development. Milestones will be established so that students work on their portfolios throughout the program and not wait until the final semester.

\section{Final Review and Evaluation}

During the final semester in the program, a panel of faculty and assessment specialists who have been advising students will review and evaluate student portfolios. Students will be asked to submit their portfolios (or provide access to them) and give an oral briefing to the panel on the contents of the portfolio. Each student must persuade the panel, through the portfolio and presentation, that he/she has achieved the intended learning outcomes, met his/her own expectations, and thought about future directions. Additionally, students would have the option of displaying their portfolios in a special exhibition.

Other professional programs use portfolio presentations to assess overall student competence and readiness to enter the profession. For example, in a teacher education program at Green Mountain (VT) College, teacher candidates are expected to prepare portfolios and present them orally to a panel of at least two instructors. ${ }^{19}$ Their presentations are rated on a three-point scale $(1=$ does not meet expectations, $2=$ meets expectations, 3 = exceeds expectations) for content, organization, materials accompanying presentations, Vermont Standards (for teacher certification), delivery, and overall presentation. To ensure consistency of observations, instructors use standard measures of inter-observer reliability. They find that students, instructors, supervisors, and programs all benefit from these portfolio presentations.

In the Aero/Astro Department, portfolios will be assessed with rubrics that standardize the process. As mentioned earlier, the issue of whether or not students will receive a grade or credit for their portfolios and presentations has not yet been decided. Most artifacts in the portfolio will have been graded earlier in courses, internships, research projects, and other extracurricular opportunities. Evaluation criteria include the extent to which the portfolio

- addresses the 16 CDIO program outcomes

- contains artifacts that demonstrate achievement of program outcomes

- shows evidence of reflection

- has clear statements of learning and application

- shows that students are able to integrate experiences and see connections

- is clearly organized

Proceedings of the 2002 American Society for Engineering Education Annual Conference \& Exposition Copyright $\left({ }^{\circ}\right.$ 2002, American Society for Engineering Education 
- is clearly presented

- has the qualities of professional engineering work

By the time students reach their final semester in the program, they have already had several prior experiences with formal oral presentations and technical briefings.

\section{Key Challenges}

Despite the successful experiences of other institutions and the proven benefits of portfolio assessment for students, instructors, and programs, implementation in our aerospace engineering program faces some key challenges:

- adoption of a new assessment strategy by faculty and students

- time commitment for faculty and students

- fair and consistent evaluation of portfolios

- ability to show evidence that portfolio assessment yields significant data for program evaluation

Faculty and students in Aeronautics and Astronautics have adapted well to the climate of change brought about by the educational reform efforts of the past four years. However, they will want to be convinced of the need for, and the benefits of, portfolios before committing to such a large-scale change, i.e., one that will affect all undergraduate faculty and students. We must structure the change to minimize the impact on faculty and student time - already a scarce resource. The numbers of students in the program (about 60 graduates per year) will require more than one panel of reviewers. The issue of fair and consistent evaluation of portfolios can be addressed with the use of standard criteria and rating scales and training of reviewers in their application. The last challenge - evidence for program evaluation - can be answered with correlation and validation of results with data collected from other sources, e.g., senior surveys, course evaluation data, and instructor reflective memos. A slow steady implementation schedule and support of department resources will give everyone time to prepare and make the transition.

\section{Bibliography}

1. Accreditation Board for Engineering and Technology, Engineering Criteria 2000, Baltimore, MD, 1994. Available at http://www.abet.org

2. Department of Aeronautics and Astronautics, Massachusetts Institute of Technology, The CDIO Syllabus. Available at http://web.mit.edu/aeroastro/www/cdio/overview.html

3. American Association for Higher Education, The Portfolio Clearinghouse. Available at http://www.aahe.org/teaching/portfolio_db.htm

4. Wilczynski, V., and K. J. Collela, "Using Design Portfolios to Improve Design Education", Proceedings of the 1996 American Society for Engineering Education Annual Conference and Exposition, 1996. Available at http://www.asee.org/conferences/search/

5. Newman, D., Interactive Aerospace Engineering and Design, Boston, Massachusetts, McGraw Hill, 2002, pp. 306-308.

6. Christy, A. D., and M. Lima, "The Use of Student Portfolios in Biological Engineering Education", Proceedings of the 1997 American Society for Engineering Education Annual Conference and Exposition, 1997. Available at http://www.asee.org/conferences/search/

Proceedings of the 2002 American Society for Engineering Education Annual Conference \& Exposition Copyright $\left({ }^{\circ}\right.$ 2002, American Society for Engineering Education 
7. Handley, M. K., "Portfolio Assessment as a Measure of Student and Program Success", Proceedings of the 1999 American Society for Engineering Education Annual Conference and Exposition, 1999. Available at http://www.asee.org/conferences/search/

8. Mourtos, N. J., "Portfolio Assessment in Aerodynamics", Journal of Engineering Education, v. 88 no. 2, 1999, pp. 223-229

9. Olds, B. M., and M. J. Pavelich, "A Portfolio-Based Assessment Program", Proceedings of the 1996 American Society for Engineering Education Annual Conference and Exposition, 1996. Available at http://www.asee.org/conferences/search/

10. Hopcroft F. J., "The Use of Portfolios as Assessment Tools in an Engineering Program", paper presented at the annual conference of the American Society for Engineering Education, St. Louis, June $15-18,2000$

11. Erikson, Jr., C. A., and R. L. Ness, "Portfolios: An Effective Assessment Strategy for First-Year Engineering Students", Proceedings of the American Society for Engineering Education. Available at http://www.asee.org/conferences/search/

12. Slater, T. F., Portfolios, 2000. Available at http://www.wcer.wisc.edu/nise/cl1/flag

13. Olds, B. M. "Reflection as an Assessment Measure", Proceedings of the 2000 American Society for Engineering Education Annual Conference and Exposition, 2000. Available at http://www.asee.org/conferences/search/

14. American Association for Higher Education, The Urban Universities Portfolio Project. Available at http://www.imir.iupui.edu/portfolio/

15. Electronic Portfolio Assessment Committee. Available at http://www.eportconsortium.org

16. Young, J. R., "Creating Online Portfolios Can Help Students See 'Big Picture', Colleges Say", The Chronicle of Higher Education, February, 21, 2002.

17. Young, J. R., "E-Portfolios Could Give Students a New Sense of Their Accomplishments", The Chronicle of Higher Education, March 8, 2002.

18. Rogers, G. M., and J. M. Williams, "Asynchronous Assessment Using Electronic Portfolios to Assess Student Outcomes", Proceedings of the 1999 American Society for Engineering Education Annual Conference and Exposition, 1999. Available at http://www.asee.org/conferences/search/

19. Fahey, P.A., and J. C. Fingon, "Assessing Oral Presentations of Student-Teacher Showcase Portfolios", The Educational Forum, v. 61, Summer 1997, pp. 354-359.

\section{DORIS R. BRODEUR}

Doris R. Brodeur is the Director of Learning Assessment in the Department of Aeronautics and Astronautics at MIT. She is responsible for designing and implementing assessment of the department's educational initiatives. She has been conducting assessment and evaluation activities for more than twenty years in K-12 schools, higher education, corporate education, and international projects.

Proceedings of the 2002 American Society for Engineering Education Annual Conference \& Exposition Copyright (C) 2002, American Society for Engineering Education 